\title{
Measuring size and choosing category size for a transition matrix study of the seaweed Ascophyllum nodosum
}

\author{
Per Åberg \\ Department of Marine Botany, University of Göteborg, Carl Skottsbergs Gata 22, S-413 19 Göteborg, Sweden
}

\begin{abstract}
A nondestructive method for measuring the size of the brown alga Ascophyllum nodosum (L.) Le Jol. has been modified in order to estimate the dry weight of tagged individuals for a size-based demographic study. There is a very strong positive correlation between the dry weight (dw) of an individual and a crude measurement of its volume. A total of 786 individuals were sampled on 3 occasions in 2 populations and the maximum length (l) and circumference (c) (in $\mathrm{cm}$ ), and dry weight (in g) were measured. A model II regression was used to obtain the relationship betweer dry weight and $\mathrm{lc}^{2}$, and since there was a significant difference between spring and autumn measurements, 2 predictive equations were needed; for spring $\log _{e}(d w)=0.7900 \log _{e}\left(l^{2}\right)-2.8547(r=0.99)$, and for autumn $\log _{e}(d w)=0.8605 \log _{e}\left(l^{2}\right)-3.3769(r=0.99)$. It is also possible to use this method on other species of seaweeds. Two methods for choosing the width of size classes were tested. One allowed the division of a population into subpopulations and the use of more than 2 census dates, and was found to be the most appropriate for this study. The first size-class was biologically distinct and was set to $0-5 \mathrm{~g}$, which includes almost all nonfertile individuals. Four more were found by the algorithm and their lower limits are $5,15,54$, and $190 \mathrm{~g}$ and these are used in the size-based demographic study.
\end{abstract}

\section{INTRODUCTION}

The demographic behaviour of an organism is the basis of many ecological and evolutionary studies. One general method to describe the population dynamics of an organism is the Leslie Matrix model (Lewis 1942, Leslie 1945, 1948), which has been used on many different organisms. The model is based on agespecific survival and reproduction, but for many organisms there is a poor correlation between an individual's age and its probability to survive and reproduce (Sauer \& Slade 1987 and references therein). For such organisms the fate of an individual is better predicted by its size. For organisms with indeterminate growth through their lives, where individuals might shrink or fragment and still continue to grow, the use of size is preferred to age. This applies to almost all macroalgae and thus size should be used as the categorical variable in almost all demographic studies of macroalgae. The Leslie Matrix model has been extended for stage categories by Lefkovitch $(1965,1967)$ and a general matrix model for size structured populations is given in Hughes (1984). Ang (1987) used it in a study of brown seaweeds
(Sargassum spp.) and recent studies also show that size is a better categorical variable than age even for higher organisms such as vertebrates (Sauer \& Slade 1987).

Theoretically it is easy to gather the data for a stage transition matrix by measuring the size of each individual at 2 points in time, but for many macroalgae this is not always easy. The method must be nondestructive and have a high resolution. Parameters such as length, area and volume of the thallus often have a strong correlation to dry weight, although the preferred parameter depends on the species. However, the problem for macroalgae is how to measure these parameters in an easy and precise way. Photogrammetric techniques (Littler \& Littler 1985) to estimate the area or length of an individual may be useful for some species, if it is possible to distinguish individuals and the problem of layering is minimal. For some species, where the length of the thallus is highly correlated to dry weight, it is possible to use a standard measuring tape. For Ascophyllum nodosum it is difficult to use photogrammetric techniques in dense populations, and length does not correlate well enough with dry weight. Thus some sort of volume measurement must be used. Pielou 
(pers. comm. in Cousens 1984) found a high correlation between $A$. nodosum plant dry weight and a crude measure of plant volume. This paper presents a modification of the method described in Cousens (1984), which allows for its use in a stage transition matrix study.

A more general problem with stage-transition matrix studies is choosing the appropriate width of the size classes, because changes in the category size may have a significant effect on the transition probabilities. Vandermeer (1978) described a method to estimate 2 types of errors connected to category size: distribution error (DE) which is large if the chosen category size is too large, and sample error (SE) which is large if the chosen category size is too small. When these errors are estimated, it is possible to choose a category size which is an 'optimal' compromise between the 2 errors. This method has been referred to in a few papers (Bullock 1980, McGraw \& Antonovics 1983, Crouse et al, 1987, Huenneke \& Marks 1987, Manders 1987) but used in only 2 (Bierzychudek 1982, Fiedler 1987). Moloney (1986) extended Vandermeer's method to include divisions of a population into subpopulations and to use more than 2 census dates. This model has thus far only been used by Moloney (1988). In this paper both methods are tested on 2 populations of Ascophyllum nodosum and other considerations concerning category sizes are also discussed.

\section{MATERIALS AND METHODS}

This paper is part of a population dynamics study of Ascophyllum nodosum (L.) Le Jol. carried out on populations at some small islands $5 \mathrm{~km}$ west of Göteborg $\left(57^{\circ} 38^{\prime} \mathrm{N}, 11^{\circ} 45^{\prime} \mathrm{E}\right)$ and $10 \mathrm{~km}$ west of Tjärnö Marine Biological Laboratory $\left(58^{\circ} 52^{\prime} \mathrm{N}, 11^{\circ} 00^{\prime} \mathrm{E}\right)$ on the Swedish west coast. These sites are hereafter referred to as Göteborg and Tjärnö. In the autumn of 1985, 1986 and 1987 all $A$. nodosum individuals in randomly chosen $0.25 \times 0.25 \mathrm{~m}$ quadrants were tagged around their holdfasts with numbered plastic-cable ties. The size of the individuals (maximum length and circumference as described below) was measured twice each year: in spring just before gamete release, and in autumn. The individuals were followed from the tagging date to their death or to the autumn of 1988 , which was the last census date. The sex ratio was $1: 1$ at both sites, and genets (Kays \& Harper 1974) were distinguished according to the method described by Åberg (1989).

Size measurements. A crude estimate of thallus volume (Pielou pers. comm. in Cousens 1984) is achieved by measuring the maximum length (1) and the maximum circumference (c) of each individual (Fig. 1) and $I c^{2}$ will be proportional to volume. The length measure-

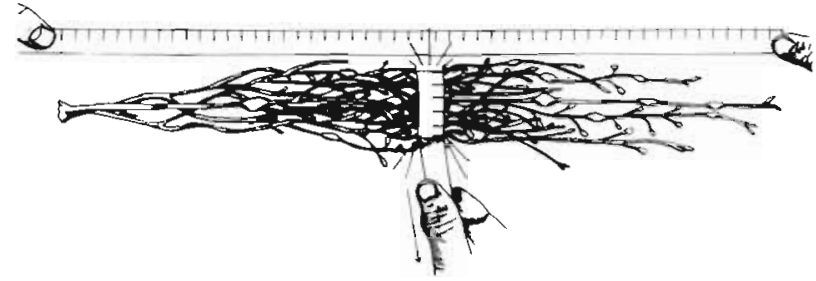

Fig. 1. Schematic drawing indicating how maximum length and maximum circumference are measured

ment is straightforward but the circumference is more crucial. All fronds from one individual are laid parallel, and the circumference of the bundle of fronds is measured in several places until the maximum is found. It is also important to tighten the measuring tape in the same way every time. To obtain the relationship between $\mathrm{lc}^{2}$ and dry weight (dw), the length and the circumference are measured on a number of individuals outside the tagged areas. These are then harvested, dried and weighed, and the relationship is obtained by regressing dry weight on volume $\left(\mathrm{lc}^{2}\right)$. In order to obtain variations between years, seasons and sites, a total of 786 individuals of all sizes was sampled at Tjärnö and Göteborg (outside but close to the area of tagged individuals) in the spring of 1985 and 1986 and in the autumn of 1988. A plastic measuring tape was used to measure maximum length and circumference and the readings were done with $0.5 \mathrm{~cm}$ precision. For very small individuals with a circumference less than $1.5 \mathrm{~cm}$ it was not possible to use the measuring tape, and their circumference was set to a value of $0.75 \mathrm{~cm}$. To minimize variation in the measurements due to different tightening of the measuring tape all measurements were done by one person. The algae were dried at $60^{\circ} \mathrm{C}$ until constant weight (approximately $48 \mathrm{~h}$ ) and weighed on a precision balance to a precision of $0.01 \mathrm{~g}$. To achieve a normal distribution, both $\mathrm{dw}$ and $1 \mathrm{c}^{2}$ were logarithmically transformed. Both $\mathrm{dw}$ and $l \mathrm{c}^{2}$ are subject to error and thus a model II regression was used (Larsen \& Marx 1986). A statistical test (Lehmann 1986), which compares the regression coefficients of 2 regression lines, was used to detect differences between sampling sites and dates in order to pool some of the data. The equation of the regression line is used to estimate the dry weight of an individual (in g) by inserting its length and circumference (in $\mathrm{cm}$ ) from the field measurement.

Category size. The basic data used in Vandermeer's (1978) and Moloney's (1986) models are transition probabilities and here they were taken from the study of the tagged populations. The 2 negatively correlated errors that both models are trying to minimize are somewhat arbitrary. The DE relates to how individuals 
are distributed within the size category. If the chosen size category is too large it is likely that only large individuals have the possibility for entering the next size class in one time interval and DE will be high. If the upper limit of the size class is set to a much lower value, the difference between small and large individuals within the class will decrease, and it is possible for small individuals to enter the next size class and DE will be lower. Theoretically, for an infinitely small category size, DE will be zero.

A transition matrix study has a finite number of individuals and the SE depends on how many individuals there are in a size category. If the size category is large it will contain many individuals and SE will be low but if the upper limit of the size class is set to a much lower value it will contain fewer individuals and SE will be higher.

The algorithms for the 2 models are rather different, but they are used in a similar way (for details see the original papers) and the following paragraph summarizes the procedure for choosing category size.

Choose the lower limit of the first size category (containing the smallest individuals) and set the upper limit to a value much greater than the expected maximum size of the category and compute DE and SE. Shorten the category size by setting the upper limit to a lower value and compute DE and SE for this category size. Continue with this until the number of individuals within the category size is less than some predetermined value or until the width of the category size is zero. Make a linear plot of DE and SE against the upper limit of the category size and the intersection point (Vandermeer's model) or the point where DE+SE is at a minimum (Fig. 2) (Moloney's model) this gives the 'optimal' category size. This procedure is repeated with the 'optimal' upper limit as a new lower limit, until all size categories are defined.

Size categories with a biological meaning should generally be preferred to those generated by a model and thus the first category size was set to 0 to $5 \mathrm{~g} \mathrm{dw}$, which includes most non-fertile individuals fown unpubl. data).

For the Vandermeer model, which only allows 2 census dates, category sizes were determined for each population at each time interval, with the restriction that each category should include at least 25 individuals at the start of the time interval, which gives a total of 12 category size estimations. With Moloney's model which allows population division in time and space, category sizes were determined for one population (pooled data for the 2 sites) with 7 census dates and for one population with 2 subpopulations (each site seen as c subpopulation) and 7 census dates, with the restriction that each category should at least include 50 individuals at the start of the time interval.
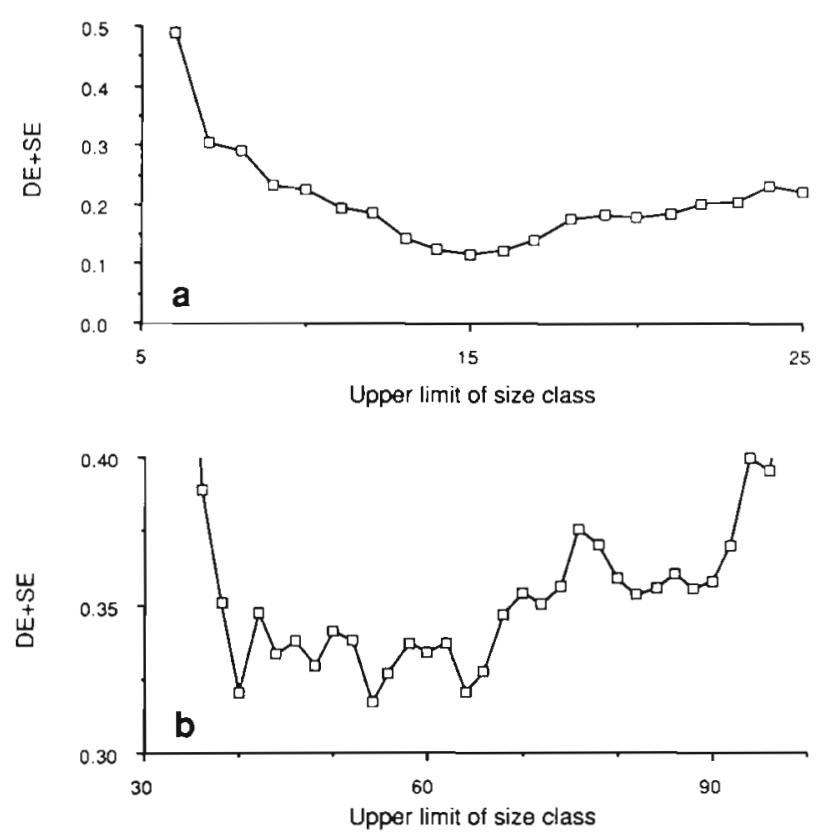

Fig. 2. Two examples of how the upper limit of a size class is chosen with Moloney's (1986) method. The upper limit is chosen where the combined distribution and sample error (DE+SE) has its lowest value. (a) The lower limit is set to 5 (g dry weight) and the upper limit is calculated to 15 (g dry weight). (b) The lower limit is set to 15 (g dry weight) and the upper limit is calculated to 54 ( $\mathrm{g}$ dry weight)

\section{RESULTS AND DISCUSSION}

\section{Size measurements}

The scatter plot of all data, for dw against $1 c^{2}$ (Fig. 3) clearly shows the relationship between the 2 variables. The data were divided into sampling sites and dates and a model II regression was performed. The results are shown in Table 1 and there is a very strong positive

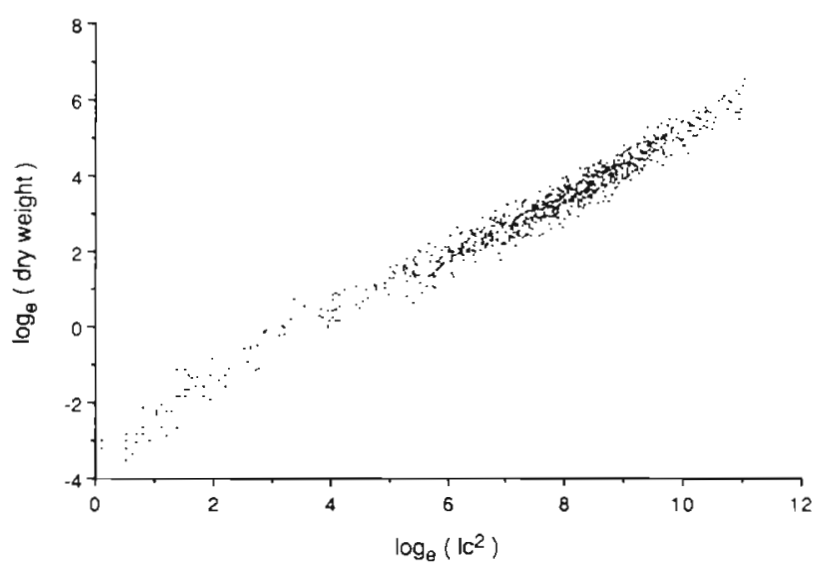

Fig. 3. Relationship between individual $\log _{e}($ dry weight) and $\log _{e}\left(l c^{2}\right)(1=$ maximum length, $c=$ maximum circumference of an individual) for all data 
Table 1. Regression lines, $\log _{e}(d w)=b\left[\log _{e}\left(l c^{2}\right)\right]+$ a for the sites Göteborg $(G)$ and Tjärnö (T) in spring (s) or autumn (a). dw: dry weight; l: max. length; $c$ : max. circumference; cc: correlation coefficient; $N$ : no. tested

\begin{tabular}{|ccccc|}
\hline Site & $\mathrm{b}$ & $\mathrm{a}$ & $\mathrm{cc}$ & $\mathrm{N}$ \\
\hline G85s & 0.7674 & -2.8832 & 0.9899 & 107 \\
G86s & 0.7854 & -2.7625 & 0.9610 & 129 \\
G88a & 0.8491 & -3.3718 & 0.9704 & 151 \\
T85s & 0.7938 & -2.9666 & 0.9930 & 132 \\
T86s & 0.7507 & -2.3785 & 0.9787 & 131 \\
T88a & 0.8679 & -3.3389 & 0.9931 & 136 \\
\hline
\end{tabular}

correlation between $\mathrm{dw}$ and $\mathrm{lc}^{2}$, with correlation coefficients ranging from 0.96 to 0.99 . The results from the model II regression may not be that different from those of a model I regression, because the correlation coefficients are high (Laws \& Archie 1981). However, according to Laws \& Archie (1981) model II regression should be used in almost all field studies and thus it is the most appropriate for this study. Table 2 shows the results from the tests of the regression coefficients. The trend that can be seen from this is that, regardless of years and sites the regression coefficients are significantly different if the data were sampled in different seasons, but not significantly different if sampled in the same season. Thus the data sampled in the spring was

Table 2. Comparisons of regression coefficients (b1 and b2 from Table 1) for the sites Goteborg (G) and Tjärmö $(T)$ in spring (s) or autumn (a). N no. tested; ns: $p>0.05 ; \cdot p<0.05$; $\cdots p<0.01 ; \cdots p<0.001$

\begin{tabular}{|c|c|c|c|c|}
\hline Site & b1 & $\mathrm{b} 2$ & $\mathrm{~N}$ & $\mathrm{p}$ \\
\hline \multicolumn{5}{|c|}{ Between sites, within a year } \\
\hline G85s - T85s & 0.7674 & 0.7938 & 235 & ns \\
\hline G86s - T86s & 0.7854 & 0.7507 & 256 & ns \\
\hline G88a - T88a & 0.8491 & 0.8679 & 283 & ns \\
\hline \multicolumn{5}{|c|}{ Between sites, between years, within a season } \\
\hline G85s - T86s & 0.7674 & 0.7507 & 234 & ns \\
\hline G86s - T85s & 0.7854 & 0.7938 & 257 & ns \\
\hline \multicolumn{5}{|c|}{ Between years, within a site, within a season } \\
\hline G85s - G86s & 0.7674 & 0.7854 & 232 & ns \\
\hline T85s - T86s & 0.7938 & 0.7507 & 259 & \\
\hline \multicolumn{5}{|c|}{ Between seasons, between years, within a site } \\
\hline G85s - G88a & 0.7674 & 0.8491 & 254 & $\cdots$ \\
\hline G86s - G88a & 0.7854 & 0.8491 & 276 & $\cdot$ \\
\hline T85s - T88a & 0.7938 & 0.8679 & 264 & $\cdots$ \\
\hline T86s - T88a & 0.7507 & 0.8679 & 263 & $\cdots$ \\
\hline \multicolumn{5}{|c|}{ Between seasons, between years, between sites } \\
\hline G85s - T88a & 0.7674 & 0.8679 & 239 & $\cdots$ \\
\hline G86s - T88a & 0.7854 & 0.8679 & 261 & $\cdots$ \\
\hline G88a - T85s & 0.8491 & 0.7938 & 279 & $\cdots$ \\
\hline G88a - T86s & 0.8491 & 0.7507 & 278 & $\cdots$ \\
\hline
\end{tabular}

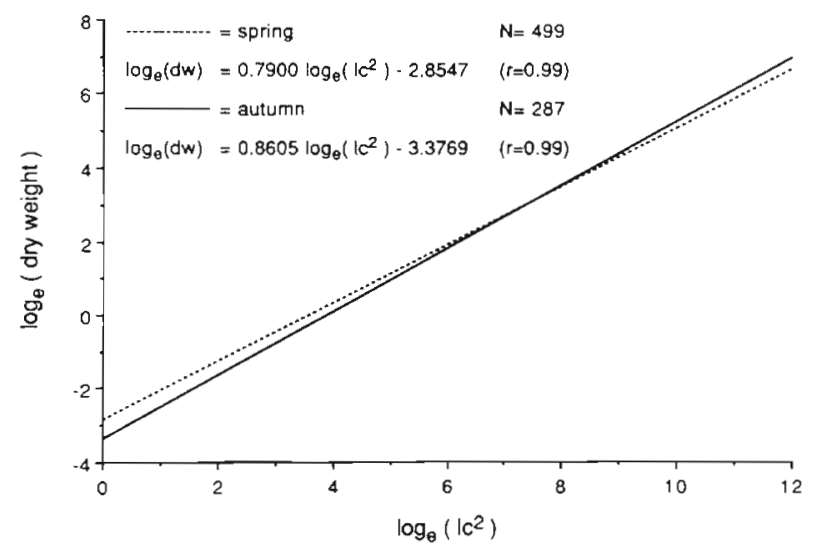

Fig. 4. Regression lines for the relationship between $\log _{e}($ dry weight $)$ and $\log _{e}\left(1 c^{2}\right)(l=\max$. length, $c=\max$. circumference). Individual points are omitted for clarity

pooled as well as the data sampled in the autumn. The regression lines are shown in Fig. 4 and the predictive equation for spring measurements is:

$$
\begin{gathered}
\log _{e}(d w)=0.7900 \log _{e}\left(l^{2}\right)-2.8547 \\
(r=0.99, N=499)
\end{gathered}
$$

and for autumn measurements is:

$$
\begin{gathered}
\log _{e}(d w)=0.8605 \log _{e}\left(l_{c}^{2}\right)-3.3769 \\
(x=0.99, N=287)
\end{gathered}
$$

The regression coefficients for Eqs. (1) and (2) are significantly different $(p<0.001)$. To estimate the dry weight of the tagged individuals of Ascophyllum nodosum Eq. (1) was used for spring measurements and Eq. (2) for autumn measurements

The main difference between this study and that of Cousens' (1984) is that here a logarithmic transformation on both $\mathrm{dw}$ and $\mathrm{lc}^{2}$, and a model II regression has been used, while Cousens used a square root transformation on $\mathrm{lc}^{2}$ and probably a model I regression. Cousens' method was also tested on the pooled data presented here, which gave the predictive equation:

$$
\mathrm{d} w=1.52 \sqrt{\left(\mathrm{lc}^{2}\right)}-37.0 \quad(\mathrm{r}=0.90, \mathrm{~N}=786)
$$

which is rather similar to:

$$
\mathrm{dw}=1.39 \sqrt{\left(\mathrm{lc}^{2}\right)}-44.8 \quad(\mathrm{r}=0.94)
$$

found by Cousen. Even though a straight line can be fitted and the correlation coefficients are high, some sort of curve seems to be more accurate (Fig. 5). Both Eqs. (3) and (4) have a negative y-intercept which means that the equations will estimate negative dry weights for individuals with a real dry weight of approximately $<15 \mathrm{~g}$. For a crude measurement of the total biomass in an area this may not be so important, but for demographic studies it is essential that no individuals have negative dry weights. The double 


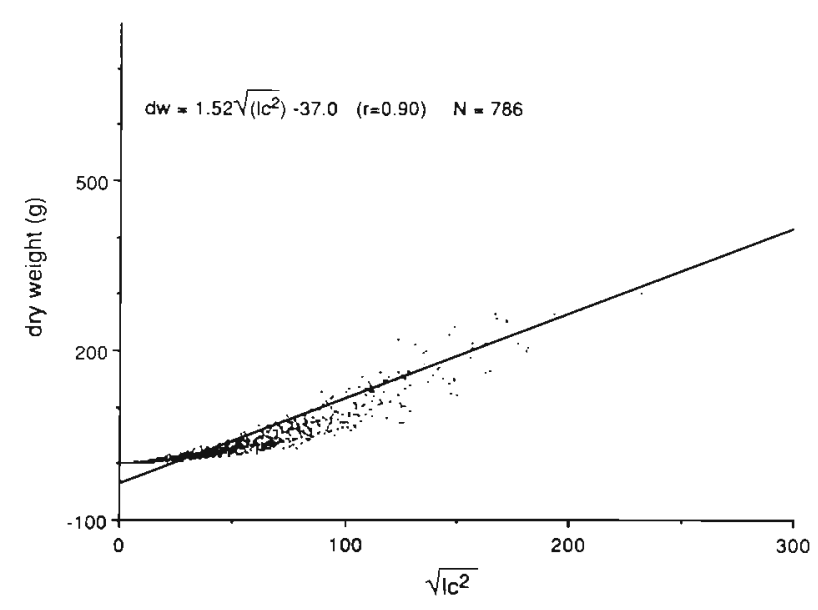

Fig. 5. Regression line found using Cousens' (1984) method on all data

logarithmic transformation, which was done to give a normal distribution of the data, also has the advantage that the regression equation rewritten in a non logarithmic way will go through origin. Thus no estimated dry weights will be negative. Eqs. (1) and (2), rewritten become:

for Eq. (1)

$$
\mathrm{dw}=0.057\left(\mathrm{lc}^{2}\right)^{0.7900}
$$

for Eq. (2)

$$
\mathrm{dw}=0.034\left(\mathrm{lc}^{2}\right)^{0.8605}
$$

These relations are shown in Fig. 6 together with that found by Cousens (1984) and the differences for the small individuals are clearly shown (Fig. 6b).

Cousens (1984) did not find significant differences in the relationship between $\mathrm{dw}$ and $\mathrm{lc}^{2}$ for various sampling dates in spring and summer or between different sites, but in this study the comparison of regression coefficients showed a pronounced difference between seasons, and that 2 regression lines, one for spring and one for autumn, were needed. The difference between Eqs. (5) and (6) is most pronounced for fertile individuals with $\mathrm{dw}>30 \mathrm{~g}$ (Fig. 6b) where individuals with equal $\mathrm{lc}^{2}$ have higher estimated dry weights in the autumn, and it is probably due to differences in tissue density. Receptables are large in the spring which may affect the density of the individual, or when tightening the bundle of fronds, more water may be included between the fronds. Other variations, within the same season, in $\mathrm{dw}$ between individuals with the same $1 c^{2}$ may be due to different shape e.g. some have a shape like a cylinder while others look like 2 cones. The relationship between $\mathrm{lc}^{2}$ and $\mathrm{d} w$ would be almost perfect if all individuals had the same shape.

One other possible source of error is the measurement of length (l) and circumference (c). The length
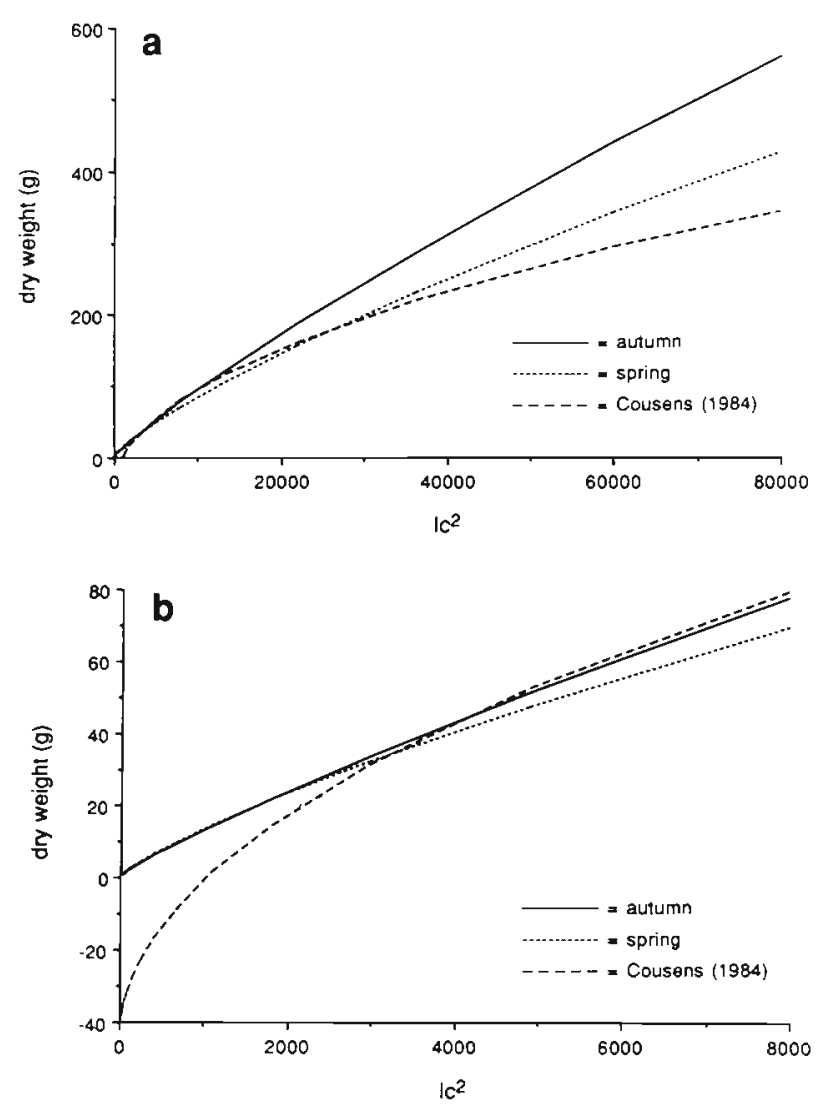

Fig. 6. A comparison of the regression lines for autumn (Eq. 2) and spring (Eq. 1) with that found by Cousens (1984) (Eq. 4) shown on a non-logarithmic graph, where (b) is a close-up of (a). Individual points are omitted for clarity

measurement can easily be done with high precision and the estimated dry weight is not as sensitive to changes in length as it is to circumference, which is squared in the calculation of volume. It is also more difficult to measure the circumference with high precision, because the measuring tape must be tightened in the same way every time. Training is recommended before measuring in the field, especially if several people are involved in the measurements. The circumference may also be overestimated due to epiphytes. There is a large variation in the amount of epiphytes between individuals, with a maximum of $20 \%$ of the total weight and a mean of $3 \pm 0.02 \%$ SE (own obs.). Large epiphytes such as the brown alga Pilayella littoralis and the red alga Ceramium rubrum are often situated in the upper parts of the 'host' plants but the maximum circumference is almost always below this region. Thus epiphytes are not a major source of error when measuring the circumference of Ascophyllum nodosum individuals.

This modified method, with increased resolution, makes it possible to follow changes in size on tagged Ascophyllum nodosum individuals. Thus it is now pos- 
sible to gather the basic data for a size-based transition matrix study. The problem of nondestructive size measurements on seaweeds is general and this method is also applicable to other species of seaweeds. The method is relevant for species with a morphology similar to $A$. nodosum, e.g. the brown algae Cystoseira spp. and Sargassum spp., the red alga Cystoclonium purpureum and many other seaweeds, but it is also applicable to filamentous red and green algae.

\section{Category size}

The 12 sets of category sizes found by using Vandermeer's method and those 2 found by using Moloney's method are shown in Table 3 with an example of how the size class limits are chosen (Fig. 2). On the average, fewer size categories were found with Vandermeer's

Table 3. The lower limit of each size class ( $g$ dry weight) found by Vandermeer's (1978) and Moloney's (1986) method. Site notation as in Table 1

\begin{tabular}{|c|c|c|c|c|c|c|c|}
\hline $\begin{array}{l}\text { Site or } \\
\text { subpopulation }\end{array}$ & $\begin{array}{l}\text { No. stage } \\
\text { categories }\end{array}$ & \multicolumn{6}{|c|}{$\begin{array}{l}\text { Estimated lower limits } \\
\text { for categories }\end{array}$} \\
\hline \multicolumn{8}{|c|}{ Vandermeer's method } \\
\hline G85a - 86s & 5 & 0 & 5 & 26 & 65 & 190 & \\
\hline T85a - 86s & 4 & 0 & 5 & 30 & 150 & & \\
\hline$G 86 s-86 a$ & 5 & 0 & 5 & 13 & 30 & 180 & \\
\hline T86s $-86 a$ & 5 & 0 & 5 & 13 & 40 & 110 & \\
\hline$G 86 a-87 s$ & 5 & 0 & 5 & 12 & 58 & 150 & \\
\hline$T 86 a-87 s$ & 5 & 0 & 5 & 12 & 30 & 74 & \\
\hline G87s $-87 a$ & 4 & 0 & 5 & 24 & 200 & & \\
\hline $\mathrm{T} 87 \mathrm{~s}-87 \mathrm{a}$ & 3 & 0 & 5 & 40 & & & \\
\hline $\mathrm{G} 87 \mathrm{a}-88 \mathrm{~s}$ & 5 & 0 & 5 & 18 & 40 & 125 & \\
\hline$T 87 a-88 s$ & 6 & 0 & 5 & 15 & 29 & 85 & 360 \\
\hline$G 88 s-88 a$ & 4 & 0 & 5 & 23 & 65 & & \\
\hline T88s - 88a & 5 & 0 & 5 & 16 & 55 & 150 & \\
\hline \multicolumn{8}{|c|}{ Moloney's method } \\
\hline Subpopulation 1 & 5 & 0 & 5 & 15 & 54 & 190 & \\
\hline Subpopulation 2 & 5 & 0 & 5 & 17 & 64 & 210 & \\
\hline
\end{tabular}

algorithm and this is probably due to the fact that fewer transitions were used in each calculation. The 2 sets of category sizes generated with Moloney's model are very similar, with only small differences in base values. The results from Vandermeer's model are more variable, but the geometric means for the third, fourth and fifth base values are 19,56 and $127 \mathrm{~g}$, in which the third and fourth are rather close to those found by Moloney's model. The fifth is lower, which also indicates the disadvantage of Vandermeer's model, in which fewer transitions are used in each calculation.

In the demographic study of Ascophyllum nodosum, different years and populations are compared and thus only one set of category sizes can be used. For this purpose Moloney's model seems to be the most appropriate, although Vandermeer's model generated similar results. To choose between the 2 sets generated with Moloney's model is difficult because the results are very similar, but the magnitude of $S E$ and $D E$ increases with increased number of subpopulations (Moloney 1986) and therefore the case with one population will be used (Table 3 ).

Studies of size based demography have become more frequent during the last years and the need for choosing appropriate category sizes is thus large. There are 4 possible solutions for choosing category size which all have been used: (1) biologically distinct stages e.g. Crouse et al. 1987; (2) using an algorithm e.g. Bierzychudek 1982 ; (3) equally large classes, in a linear or logarithmic scale e.g. McGraw \& Antonovics 1983; and (4) arbitrary size classes e.g. Hughes 1984. The methods can also be combined (e.g. this study, Method 1 and 2). Classes with a biological meaning are to be preferred, because it is easier to interpret the transition matrix. However, for many organisms it is not possible to find distinct biological classes and thus some other method must be used. Using an algorithm for choosing category size is attractive, but it is desirable to have much detailed information on the species in question so that biologically irrelevant classes, that for some reason may be generated by the model, can be discovered. For Ascophyllum nodosum only the first class is biologically distinct and thus the 2 models, where Moloney's showed to be the most relevant, were used. Biologically relevant classes for a perennial seaweed such as $A$. nodosum should be approximately equally large on a logarithmic scale. This is because the very large range of sizes and the fact that larger individuals have the ability to grow much more than smaller ones. The classes found with Moloney's model are approximately equally large on a logarithmic scale and therefore are appropriate to use.

Acknowledgements. I thank Inger Wallentinus and Per Nils son for critical comments on the manuscript and Nan Albertson for correcting my English. I am also very grateful to Jan Karlsson for his artistic drawing of Ascophyllum nodosum This study was supported in part by kapten C. Stenholms donationsfond, Hierta Retzius' stipendiefond, Wilhelm och Martina Lundgrens vetenskapsfond and stiftelsen Lars Hiertas minne.

\section{LITERATURE CITED}

Aberg, P. (1989). Distinguishing between genetic individuals in Ascophyllum nodosum populations on the Swedish west coast. Br. phycol. J. 24: 183-190

Ang, P. O. (1987). Use of projection matrix models in the assessment of harvesting strategies for Sargassum Hydrobiologia 151/152: 335-339 
Bierzychudek, P. (1982). The demography of jack-in-the-pulpit a forest perennial that changes sex. Ecol. Monogr. 52 . 335-351

Bullock, S. H. (1980). Demography of an undergrowth palm in littoral Cameroon. Biotropica 12: 247-255

Cousens, R. (1984). Estimation on annual production by the intertidal brown alga Ascophyllum nodosum (L.) Le Jolis. Botanica mar 27. 217-227

Crouse, D. T., Crowder, L. B., Caswell, H. (1987). A stagebased population model for loggerhead sea turtles and implications for conservation. Ecology 68: 1412-1423

Fiedler, P. L. (1987). Life history and population dynamics of rare and common mariposa lilies (Calochortus Pursh: Liliaceae). J. Ecol. 75: 977-995

Huenneke, L. F., Marks, P. L. (1987). Stem dynamics of the shrub Alnus incana ssp. rugosa: transition matrix models. Ecology 68: 1234-1242

Hughes, T P. (1984). Population dynamics based on individual size rather than age: a general model with a reef coral example. Am. Nat. 123: 778-795

Kays, S., Harper, J. L. (1974). The regulation of plant and tiller density in a grass sward. J. Ecol. 62: 97-105

Larsen, R. J., Marx, M. L. (1986). An introduction to mathematical statistics and its applications, 2nd edn. Prentice-Hall International Inc., Englewood Cliffs

Laws, E. A., Archie, J. W. (1981). Appropriate use of regression analysis in marine biology. Mar. Biol. 65: 13-16

Lefkovitch, L. P. (1965). The study of population growth in organisms grouped by stages. Biometrics 21: 1-18

Lefkovitch, L. P. (1967). A theoretical evaluation of population

This article was submitted to the editor growth after removing individuals from some age groups. Bull. ent. Res. 57: 437-445

Lehmann, E. L. (1986). Testing statistical hypothesis, 2nd edn. John Wiley \& Sons, New York, p. 399

Leslie, P. H. (1945). On the use of matrices in certain population mathematics. Biometrika 33: 183-212

Leslie, P. H. (1948). Some further notes on the use of matrices in population mathematics. Biometrika 35: 213-245

Lewis, E. G. (1942). On the generation and growth of a population. Sankya 6: 93-96

Littler, M. M., Littler, D. S. (1985). Nondestructive sampling. In: Littler, M. M., Littler, D. S. (eds.) Ecological field methods: Macroalgae. Cambridge University Press, Cambridge, p. $161-175$

Manders, P. T. (1987). A transition matrix model of the population dynamics of the Clanwilliam ceder (Widdringtonia cedarbergensis) in natural stands subject to fire. For. Ecol. 20: 171-186

McGraw, J. B., Antonovics, J. (1983). Experimental ecology of Dryas octopetala ecotypes. II. A demographic model of growth, branching and fecundity. J. Ecol. 71: 899-912

Moloney, K. A. (1986). A generalized algorithm for determining category size. Oecologia (Berl.) 69: 176-180

Moloney, K. A. (1988). Fine-scale spatial and temporal variation in the demography of a perennial bunchgrass. Ecology 69: $1588-1598$

Sauer, J. R., Slade, N. A. (1987). Size-based demography of vertebrates. A. Rev. Ecol. Syst. 18: 71-90

Vandermeer, J. (1978). Chosing category size in a stage projection matrix. Oecologia (Berl.) 32: 79-84

Manuscript first received: November 20, 1989

Revised version accepted: March 9, 1990 